\title{
TEOR DE MACRO E MICRONUTRIENTES EM FOLHAS DE DIFERENTES IDADES DE ALGUMAS ESSENCIAS FLORESTAIS NATIVAS*
}

\author{
Antonio A. Carpanezzi \\ JosÉ O. BRITO \\ Plínio FERNANDES \\ WALTER JARK FilHo
}

\section{RESUMO}

No presente trabalho, foram determinados os teores de $\mathrm{N}, \mathrm{P}$, $\mathrm{K}, \mathrm{Ca}, \mathrm{Mg}, \mathrm{Fe}, \mathrm{Zn}, \mathrm{Cu}$ e $\mathrm{Mn}$ em folhas de diferentes idades nas espécies: Astronium rurndeuva, Aspidosperma ramiflorum Muell, Tabcbuia flavescens Grise, Terminalia catappa e Joannesia princeps Vell. Os teores médios observados encontram-se dentro dos valores considerados médios para outrats espécies, quando se adota a amplitude máxima de observações feitas por diversos autores. Com relação aos teores de nutrientes em follhas de idade diferente numa mesma espécie, com exceção de Terminalia catappa, não foram observadas variações regulares para os três níveis de idade fisiológica considerados. Os valores das folhas da espécie Astronium urindeuva evidenciaram suas características de planta calcícola.

\section{INTRODUÇÃO}

Em virtude das escassas informações existentes sobre exigências nutricionais de espécies florestais, especialmente essências nativas, procurou-se colher alguns dados sobre o teor de nutrientes nas folhas de algumas essências existentes no parque de E.S.A. "Luiz de Queiroz".

Algumas das espécies estudadas não se encontram na sua região de ocorrência natural, bem como implicações de ordem fenológicas e características de solo e amostragem farão com que provavelmente os dados observados não correspondam às exigências reais. As informações obtidas, são válidas desde que o leitor tome cuidado na interpretação dos dados e que os utilize como informação inicial para realizar investigações mais complexas e criteriosas.

\footnotetext{
* Trabalho conduzido pelos alunos do Curso Pós-Graduado em Engenharia Florestal, disciplina "Nutrição Mineral em Silvicultura" - Profs. H.P. Haag e G.D. de Oliveira. E.S.A. "Luiz de Queiroz", USP.; Entregue para publicação em 30/08/1976.
} 
Como o conhecimento das espécies é importante para a interpretação dos resultados, foi realizada uma revisão da literatura.

Aroeira - Astronium urindeuva (Fr. All.) Engl. (Anacardiaceae). Segundo RIZZINI (1973) a aroeira tem ampla distribuição na América do Sul, adaptando-se a climas diversos como os de cerrado, caatinga e floresta pluvial (2000 $\mathrm{mm}$ de chuva); o porte varia de modo correspondente chegando a $30 \mathrm{~m} \times 100 \mathrm{~cm}$ na floresta pluvial. Sua principal ocorrência no Estado de São Paulo é, hoje, no Oeste, indica MAINIERI (1970); no começo do século PEREIRA (1929) apontava grandes concentrações na região de Piracicaba.

Devido a sua ampla distribuição geográfica e o fato de não ser encontrado em regiões intermediárias de ocorrência, HUECK (1973) levanta dúvidas quanto à sua classificação como entidade botânica única. Persistindo sua área de distribuição atual prevê-se a ocorrência de variação intra-específica, acarretando comportamentos fisiológicos particulares a cada raça.

Por sua distribuição na área dos cerrados HERINGER \& FERREIRA (1973) classificam-se como planta calcícola. As considerações de GOODLAND (1971) atualizam a caracterização de plantas calcícolas e calcífugas quanto à nutrição mineral.

Sob inverno seco bem definido a aroeira apresenta-se com espécie totalmente caducifolia. HERINGER \& FERREIRA (1973) apontam a seqüência: perda total de folhas em julho-agosto e florescimento no início da primavera, seguido de rápida frutificação; ao amadurecerem os frutos, a árvore cobre-se de folhagem avermelhada.

O experimento de BARROS (1970) patenteia o lento crescimento da espécie. Isto explica porque não é utilizada em plantas comerciais, não obstante o alto valor de sua madeira.

Guatambu - Aspidosperma ramiflorum Muell. Arg. (Apocynaceae). As observações de CARPANEZZI (1975) evidenciam tratar-se de espécie altamente exigente em fertilidade de solo e quanto ao sombramento inicial de suas mudas. Estas condições para sua ocorrência natural são confirmadas por SOUZA (1973). Segundo RIZZINI (1973) ocorre na floresta pluvial atlântica e em florestas pluviais ou semideciduas do interior, estendendo-se até a Bolívia.

Em formações naturais em regiões de inverno seco, CARPANEZZI (1975) encontrou apenas leve caducifolia no período crítico junho-setembro; a formação de seus frutos iniciou-se em janeiro-fevereiro dando-se a deiscência em agosto-setembro.

Chapéu-de-sol - Terminalia catappa (Combretaceae). SOUZA (1962) mostra sua grande utilidade na arborização de praias, por adaptar-se bem a terrenos ácidos, arenosos, pobres em matéria orgânica e sais minerais. E amplamente empregada, para este fim, em climas tropical e sub-tropical. 
A caducifolia das folhas de chapéu-de-sol é esquematizada por SOUZA (1973): na entrada do inverno há queda das folhas adultas, coriáceas, grandes e de coloração amarelo-bronzeada; no Estado de São Paulo, os frutos, grandes e numerosos, formam-se entre os meses de abril e junho.

Ipê amarelo - Tabebuia flavescens Grise (Bignoniaceae). Segundo RIZZINI (1971) o gênero Tabebuia engloba 60 espécies, habitantes da América tropical. SOUZA (1963a, 1963b) eleva este número a 150, frizando haver inúmeras espécies tratadas por ipê amarelo, com grande diversidade de habitats.

A literatura consultada não traz qualquer informação sobre Tabebuia flavescens Grise. Na região de Piracicaba pode-se, somente, generalizar a caducifolia completa do gênero no período crítico de inverno, acompanhada ou, mais frequentemente, seguida por floração. Após esta, ocorre a frutificação.

Anda-açu ou Boleira - Joanesia princeps Vell. (Euphorbiaceae). FREIRE (1933) generaliza sua ocorrência esparsa para muitos estados do Brasil, mas com grandes aglomerações no Espírito Santo, nas matas virgens próximas ao Vale do Rio Doce. ANDRADE \& VECCHI (1916) indicam-na como bastante comum no Estado de São Paulo, destacando seu rápido crescimento e as propriedades de sua madeira. Segundo PEREIRA (1929) e MAINIERI (1971) as árvores florescem em junho-setembro e frutificam em junho-julho, fornecendo grandes cápsulas contendo amêndoas oleosas.

MATERIAL E MÉTODOS

Foram coletadas folhas das espécies:

$\begin{array}{lll}\text { Nome vulgar } & \text { Família } & \text { Nome coentífico } \\ \text { Aroeira do Campo } & \begin{array}{l}\text { Anacardiaceae } \\ \text { Guatambu }\end{array} & \begin{array}{l}\text { Astronium uriendeuva } \\ \text { Aspidosperma ramiflorum } \\ \text { Muell }\end{array} \\ \text { Ipê amarelo } & \text { Bignoniaceae } & \text { Tabebuia flavescens, Grise } \\ \text { Chapéu-de-sol } & \text { Combretaceae } & \text { Terminalia catappa } \\ \text { Anda assu } & \text { Euphorbiaceae } & \text { Joanesia princeps } \text { Vell }\end{array}$

O material coletado em árvores existente no parque da Escola Superior de Agricultura "Luiz de Queiroz", em solo classificado como Latossol Roxo - Série Luiz de Queiroz transitando para Litossol Série Lageadinho, segundo RANZANI et alii (1965). 
As amostras de folhas foram obtidas no final do verão (março 1976). Foi realizada uma amostragem em diferentes locais da copa, sendo as folhas classificadas como jovens, medianas e maduras de acordo com características como coloração, tamanho e posição no ramo.

Esta amostragem foi feita num só indivíduo de cada espécie, tomando-se 3 repetições de cada tipo de folha.

Após a amostragem e classificação as folhas foram acondicionadas em sacos plásticos identificados e transportadas para o Laboratório de Nutrição Mineral de Plantas do Departamento de Química, onde foram realizadas as análises.

O material sofreu um processo convencional de lavagem para análise de teores de macro e micronutrientes, segundo métodos descritos em SARRUGE \& HAAG (1974).

\section{RESULTADOS E DISCUSSÃO}

Os resultados das análises encontram-se nas tabelas 1 e 2 .

Tabela 1 - Teor de macro e micronutrientes na matéria seca em folhas novas (A), medianas (B) e maduras (C).

\begin{tabular}{|c|c|c|c|c|c|c|c|c|c|c|}
\hline \multirow{2}{*}{ Espécie } & \multirow{2}{*}{ Folhas } & \multicolumn{5}{|c|}{$\%$} & \multicolumn{4}{|c|}{$\mathrm{ppm}$} \\
\hline & & $N$ & P & $\mathrm{K}$ & $\mathrm{Ca}$ & $\mathrm{Mg}$ & $Z_{11}$ & $\mathrm{Fe}$ & $\mathrm{Cu}$ & $M n$ \\
\hline Aspidosperma & A & 2,44 & 0.17 & 1,55 & 1,62 & 0,45 & 29 & 147 & 7 & 53 \\
\hline \multirow[t]{2}{*}{ ramiflorum } & $B$ & 2,87 & 0,18 & 1,73 & 1,78 & 0,47 & 36 & 158 & 6 & 52 \\
\hline & C & 2,67 & 0,20 & 1,87 & 1,80 & 0,47 & 38 & 163 & 5 & 104 \\
\hline Tabebuia & A & 2,43 & 0.16 & 1,98 & 0,53 & 0,26 & 43 & 236 & 5 & 880 \\
\hline \multirow[t]{2}{*}{ fluvescens } & B & 2,46 & 0.15 & 1,72 & 0,51 & 0,26 & 41 & 242 & 3 & 889 \\
\hline & C & 2,71 & 0,14 & 1,62 & 0,61 & 0,27 & 42 & 246 & 5 & 954 \\
\hline Joanesia & A & 2.76 & 0,16 & 1,75 & 1,05 & 0,33 & 37 & 212 & 12 & 111 \\
\hline \multirow[t]{2}{*}{ princess } & $B$ & 2,59 & 0.18 & 1,82 & 1,06 & 0,36 & 71 & 186 & 6 & 125 \\
\hline & $\mathrm{C}$ & 2.44 & 0,17 & 1,97 & 1,18 & 0,38 & 40 & 236 & 6 & 155 \\
\hline Astronizm & A & 2,52 & 0,29 & 1,32 & 0,71 & 0,15 & 35 & 146 & 9 & 33 \\
\hline \multirow[t]{2}{*}{ urundeuva } & B & 2,39 & 0,26 & 1,28 & 0,75 & 0,16 & 40 & 239 & 6 & 155 \\
\hline & C & 2,28 & 0,34 & 1,43 & 0,66 & 0,18 & 34 & 131 & 8 & 32 \\
\hline Terminatia & A & 2,30 & 0,27 & 2,15 & 0,65 & 0,20 & 34 & 77 & 9 & 32 \\
\hline \multirow[t]{2}{*}{ catuppa } & B & 2,21 & 0.23 & 1,82 & 1,08 & 0,23 & 43 & 76 & 7 & 41 \\
\hline & $\mathrm{C}$ & 1,11 & 0,21 & 1,43 & 1,92 & 0,36 & 41 & 123 & 5 & 78 \\
\hline
\end{tabular}


Tabela 2 - Teor de nutrientes na matéria seca em essências florestais, média dos 3 tipos de folhas.

\begin{tabular}{|c|c|c|c|c|c|c|c|c|c|c|}
\hline \multirow{2}{*}{ Espécie } & \multirow{2}{*}{ folhas } & \multicolumn{5}{|c|}{$\%$} & \multicolumn{4}{|c|}{$\mathrm{ppm}$} \\
\hline & & $N$ & $\mathrm{P}$ & $\mathrm{K}$ & $\mathrm{Ca}$ & $\mathrm{Mg}$ & $Z_{n}$ & $\mathrm{Fe}$ & $\mathrm{Cu}$ & $\mathrm{Mn}$ \\
\hline \multicolumn{11}{|c|}{ Aspidosperma } \\
\hline ramiflorum & & 2,66 & 0.18 & 1,72 & 1,73 & 0,46 & 34 & 156 & 6 & 70 \\
\hline \multicolumn{11}{|l|}{ Tabebuia } \\
\hline flicescens & & 2,53 & 0,15 & 1,77 & 0,55 & 0,26 & 42 & 241 & 4 & 908 \\
\hline \multicolumn{11}{|l|}{ Joanesia } \\
\hline princeps & & 2.60 & 0,17 & 1,85 & 1,10 & 0,36 & 49 & 212 & 8 & 130 \\
\hline \multicolumn{11}{|l|}{ Astronium } \\
\hline Itrundeuva & & 2,40 & 0,30 & 1,34 & 0,71 & 0,16 & 36 & 138 & 8 & 35 \\
\hline \multicolumn{11}{|l|}{ Terminalia } \\
\hline cathpta & & 1,87 & 0.24 & 1,80 & 1,22 & 0,26 & 39 & 92 & 7 & 50 \\
\hline
\end{tabular}

O teor médio de cada nutriente (Tabela 2) encontra-se dentro dos valores considerados médios para outras espécies adotando-se a amplitude máxima do conjunto das observações de JONES (1972), LEAF (1973), MALAVOLTA et alii (1975).

Não há dados referentes às espécies em estudo. Pode-se porém, estimar que os valores encontrados enquadram-se dentro da faixa adequada para cada especie, com restrições decorrentes da amostragem, uma vez que não foram notados sintomas visuais de deficiência ou toxidez mineral nos indivíduos amostrados. O teor de cada nutriente é ligado à idade do vegetal, segundo RAMEZOV et alii (apud CURLIN, 1970); segundo LUNDEGADH (1951) e JONES (1972) ocorre, ainda, uma variação estacional. particular de cada espécie, relacionada aos seus processos fenológicos.

Os indivíduos amostrados aparentam ter atingido a maturidaac, embora não se possa precisar a sua idade cronológica. Todavia, sendo a fenologia bastante diferenciada entre as espécies não há possibilidade de comparação segura de folhas consideradas de mesma idade fisiológica, entre as espécies. Dentro de uma mesma espécie, apenas pode-se considerar três graus distintos de maturidade, mas não afirmar que a folha mais velha estivesse fisiologicamente madura, o que significaria translocação obrigatória de certos nutrientes para estruturas fisiologimente mais jovens. Mesmo fixando as condições como ótimas - folhas fisiologicamente maduras, já próximas da senescência e abcisão, cedendo 
elementos móveis às estruturas mais recentes - não se pode precisar até que ponto haveria translocação para flores e frutos, em detrimento da transferência à folha com diferente intensidade.

Baseando-se nestas variações fenológicas carticulares a cada espécie, compreende-se a oscilação no cômputo final (Tabela 1) em que caracterizam-se os níveis previstos, referentes às três idades fisiológicas bem separadas, para um ou alguns elementos, mas não para todos. Estas oscilações ocorrem para as espécies estudadas, exceto Terminalia catappa, na qual são marcantes as diferenças entre as folhas representativas das idades fisiológicas, ligados ao tamanho, consistência e coloração, além de suas posições nos ramos. A análise foliar de um indivíduo localizado fora de seu habitat selvagem nem sempre revela relação com as condições de ocorrência natural da espécie. Os dados referentes à Aspidosperma ramiflorum e Terminalia catappa (Tabela 2), considerados agora como representativos, servem de exemplo: não refletem as condições (nutricionais e não nutricionais) altamente contrastantes dos habitats destas espécies. O envolvimento de outras espécies na comparação dilui ainda mais as possíveis diferenças visualizadas.

Outras espécies, contudo, parecem demonstrar uma continuidade fisiológica na nutrição mineral, mesmo quando examinadas em ocorrência não natural. A aroeira, Astronium urindeuva, é um bom exemplo: seu teor de cálcio (Tabela 2), não é elevado, e seus teores extremos e opostos de fósforo e manganês reafirmam sua caracterização como planta calcícola.

De modo análogo, Ipê amarelo (Tabebuia flavescens Grise) apresenta comportamento oposto. A definição de sua ocorrência natural (provavelmente o cerrado) e um exame comparativo de alumínio entre suas folhas e as de Aroeira poderão trazer maiores esclarecimentos.

\section{CONCLUSÕES}

- A variação irregular dos nutrientes dentro dos níveis de folhas está associado à fenologia particular de cada espécie.

- Astronium urindeuva apresentou em suas folhas um teor de nutrientes condizentes com suas características calcícolas.

- Os teores de nutrientes encontrados na análise foliar de Tabebuia flavescens sugerem um comportamento calcífugo da espécie.

\section{AGRADECIMENTOS}

São devidos ao Prof. Dr. Fábio Poggiani do Departamento de Silvicultura da E.S.A. "Luiz de Queiroz" pelas sugestões apresentadas. 


\section{SUMMARY}

\section{LEAF ANALYSIS OF FIVE NATIVE FOREST SPECIES}

Leaves of several tree species (Astronium urindeuva, Aspidosperma ramiflorum Muell, Tabebuia flavescens Grise, Terminalia catappa and Joannesia princeps Vell) have been analysed for $\mathrm{N}, \mathrm{P}, \mathrm{K}, \mathrm{Ca}, \mathrm{Mg}, \mathrm{Fe}, \mathrm{Zn}, \mathrm{Cu}$ and $\mathrm{Mn}$.

Results indicated that the mean concentration of these elements are within the average range of nutrients concentration determined by several authors. Nutrients content have no regular variation among leaves of different ages, except for Terminalia catappa. Astronium urundeuva is considered a calcicolous plant and this caracteristic could be inferred by the nutrient contents of its leaves.

\section{LITERATURA CITADA}

ANDRADE, E.N. \& VECCHI, O. 1916 - Les Bois Indigènes de São Paulo, São Paulo, Secretaria da Agricultura, Comércio e Trabalho do Estado de São Paulo, 376 p.

BARROS, D.P. 1970 - Ensaio de espaçamento inicial para “Aroeira”. Silvicultura em São Paulo, Vol. 7, 39-41.

CARPANEZZI, A. 1975 - Relatório Geral à Duraflora Silvicultura e Comércio Ltda. datilografado.

CURLIN, J.W. 1970 - Nutrient cyling as a factor in Site Productivity and Forest Fertilization. In Chester, T.Y. \& DAVEY, C.B. (editores). 1970. The Growth and Forest Soils. Oregon State University Press. 527 p.

FREISE, F.W. 1933 - Plantas medicinais brasileiras. In Boletim da Agricultura, São Paulo, 34 (único) 265-6.

GOODLAND, R. 1971 - Oligotrofismo e Alumínio no Cerrado. In III Simpósio sobre o Cerrado, 44-60. Editora Edgard Blucher, Editora da USP.

HERINGER, E.P. \& FERREIRA, M.B. 1973 - Aroeira, Gonçalo e Gibatão: o gênero Astronium e sua importância florestal. In Cerrado, V (22) : 24-33.

HUECK, K. 1972 - As florestas da América do Sul. São Paulo, Editora Polígono, Editora da Universidade de Brasília. $466 \mathrm{p}$.

JONES, J.R. J.B. 1972 - Plant Tissue Analysis for micronutrients. In MORIVELDT. J.J. (editor). 1972. Micronutrients in Agriculture. Madison, Soil Science Society of America, Inc.

LEAF, A.L. 1973 - Plant Analysis as an aid in Fertilizing Forests. In WALSH, L.M. e BEATON, D.B. (editores). 1973. Soil Testing and Plant Analysis. Madison, Soil Science of America, Inc.

LUNDEGADH, H. 1951 - Leaf Analysis. London, Helger e Watts Ltd. 172 p. 
MAINIERI, C. 1970 - Madeiras Brasileiras. São Paulo, Instituto Federal. 108 p.

MALAVOLTA, E., H.P. HAAG, F.A.F. MELlO, M.O.C. BRASIL SOBR. ${ }^{\circ} 1973-$ Nutrição Mineral e Adubasão das Plantas Cultivadas. São Paulo, Livraria Editora Pioneira.

PEREIRA, H. 1929 - Pequena contribuição para um dicionário das plantas úteis do E.stado de São Paulo. São Paulo, Secretaria da Agricultura, Comércio e Trabalho do Estado de São Paulo. 779 p.

RANZINI, G., O. FREIRE, T. KINJO. 1966 - Carta de solos do municipio de Piracicaba. Piracicaba, ESALQ, USP. Mimeografado. 61 p.

RIZZINI, C.T. 1971 - Arvores e madeiras úteis do Brasil. São Paulo, Editora Edgard Blucher. Editora da USP. 294 p.

SARRUGE, J.R., H.P. HAAG - Análises Químicas em Plantas. Setor de Nutrição Mineral de Plantas, Depto. de Química, ESALQ, USP, Piracicaba, 1974.

SOUZA, H.M. - O notável ajardinamento das praias da cidade de Santos. O Estado de São Paulo. São Paulo, 1961. Suplemento Agrícola n. 308.

SOUZA, H.M. - Ipê : extraordinária flor ornamental. O Estado de São Paulo. São Paulo, 1963a. Suplemento Agrícola 11. ${ }^{\circ} 443$.

SOUZA, H.M. - Ipês amarelos e brancos. O Estado de São Paulo. São Paulo, 1963 b. Suplemento Agrícola n. ${ }^{\circ} 449$.

SOUZA, H.M. - Os guatambus ornamentais. O Estado de São Paulo. São Paulo, 1973 a. Suplemento Agrícola 1. $0^{\circ} 945$.

SOUZA, H.M. - O chapéu de sol. () Estado de São Paulo. São Paulo, 1973b. Suplemento Agrícola 11. 948. 